\title{
7 Wind, Rain and Solar Radiation Measurements
}

\subsection{Preliminary Discussion}

Before addressing the technological aspects of the subjects to be considered in this chapter, it is relevant to discuss some more general aspects. Because the title of our book refers to modern instrumentation, we have been tempted to obviate some topics such as mechanical anemometers or tipping bucket rain gauge. But upon reflection, the decision to include mechanical equipment with some level of detail prevailed. The reasons behind this decision were mainly three: 1) It is not clear that reliable existing methods will be soon replaced by new ones; 2) In general, postgraduate students are not yet familiar with the use of these instruments and how mechanical information is converted into electrical information; 3) We think that descriptions result necessary to advice readers about instrument limitations and operational problems.

\subsection{Wind Measurements}

\subsubsection{Introduction}

Wind velocity is a vector which is among the most traditionally measured parameters in meteorology. There are some anemometers that calculate the resulting vector by adding two horizontal wind velocity components measured in two perpendicular directions. It is also common practice to measure the average horizontal wind in polar coordinates, namely, wind speed (the magnitude of the wind vector) and wind direction (the orientation of the wind vector) (US EPA, 2000.). Incidentally, in meteorology wind direction is defined as the direction from which wind blows, and it is measured in degrees clockwise from true north.

When information on the variability of the wind is required, the peak gust and the standard deviations of wind speed and direction are considered (WMO, 2008). Instruments used for in situ measuring of wind are called anemometers, and in general may be grouped into mechanical and non-mechanical sensors.

In order to average natural turbulent wind fluctuations it is required to extend the averaging during several minutes. Usually, the wind average period for forecasting purposes is 10 minutes, and for climatological statistics is 60 minutes. When it is desired to know peak gusts, a running average filter with a certain integration period $T$ must be used. This period is defined as the gust duration, and the maximum observed wind speed over a period of time (such as one hour) is defined as the peak gust. For example, if a running filter of $30 \mathrm{~s}$ is used to average the output of an anemometer for an observation time of one hour, and the maximum value registered 
is $100 \mathrm{~km} / \mathrm{h}$, it is said that in that particular hour there was a peak gust of $100 \mathrm{~km} / \mathrm{h}$ with $30 \mathrm{~s}$ of duration.

As it happens with other instruments, the time constant could be used to characterize anemometers (Section (2.4.5)). For a first-order system it is the time required for a device to reach about 63 per cent of a step-function change. One limitation of the time constant is that for rotating anemometers it was found in wind tunnel tests that it depends on wind speed (the variable one wants to measure). Then another particular constant not dependent on wind is defined for rotating anemometers: the response length or distance constant $\left(l_{0}\right)$. It is the length of fluid flow (the length of the cylinder of air) which has to pass through the anemometer before it has attained the 63 per cent of its final response to a step-function change of the input speed (it is usually measured in meters). The cup anemometer could be considered a first-order filter whose time constant $\tau$ is given by

$$
\tau=\frac{l_{0}}{V}
$$

where $V$ is the mean wind speed. It should be noted that $l_{0}$ is independent of the wind speed (Kristensen \& Hansen, 2002).

It was also found that the natural frequency $\omega_{0}$ of the vane system is proportional to $V$, and then a distance constant $\left(l_{v}\right)$ for the vane is also defined as (Kristensen, 1993)

$$
l_{\mathrm{v}}=\frac{V}{\omega_{0}}
$$

These two constants help compare anemometers performance and fit the most adequate anemometer for the application needs.

\subsubsection{Mechanical Anemometers}

Current mechanical anemometers usually have two parts: the actual mechanical part that produces a mechanical response to wind excitation and the transducers to convert mechanical variables into electrical ones. The first usually consists of a rotating device to measure wind speed and a vane to measure wind direction; and the second is composed of sensors and circuits which provide electrical outputs from the mechanical inputs.

With respect to the mechanical parts, there are basically two aerodynamic solutions: one is the cup and vane anemometer, and the other is the aerovane.

Regarding the sensors and circuits devoted to transform a mechanical rotation into an electrical signal, there are several solutions already explained in Section (4.14). Every manufacturer uses his own sensors according to his experience and the anemometer application. For example, when electrical energy is not available and batteries and solar panels are not of great help, as could be in boreal or austral winters, it could be useful to use anemometers that produce their own electrical energy from the wind. This solution requires paying a price because to produce electrical energy it is 
required to take mechanical energy from the wind. These sensors impose an electrical load on the mechanical device which tends to brake the rotor; as a result, low wind velocities cannot be measured. On the contrary, when it is desired to measure low velocity and electrical energy is not a constraint, sensors with the minimum inertia and frictional torque should be selected.

\subsubsection{Aerovane}

The anemometer known as aerovane consists of a body which aligns itself to the main wind direction due to a vane or tail (Fig. 7.1). The wind speed is measured by a propeller which may have two or more blades. The propeller is placed on the front of the body and its transference has a linear behavior in a certain operating range; it has a starting threshold below which the force produced by the wind is not enough to make the propeller rotate, and extends up to some maximum speed where the rotation can no longer follow the increasing wind speed. The transference of the propeller depends on the angle between the plane containing the propeller and the wind direction; the propeller axis must be always parallel to the wind direction for the calibration to be valid.

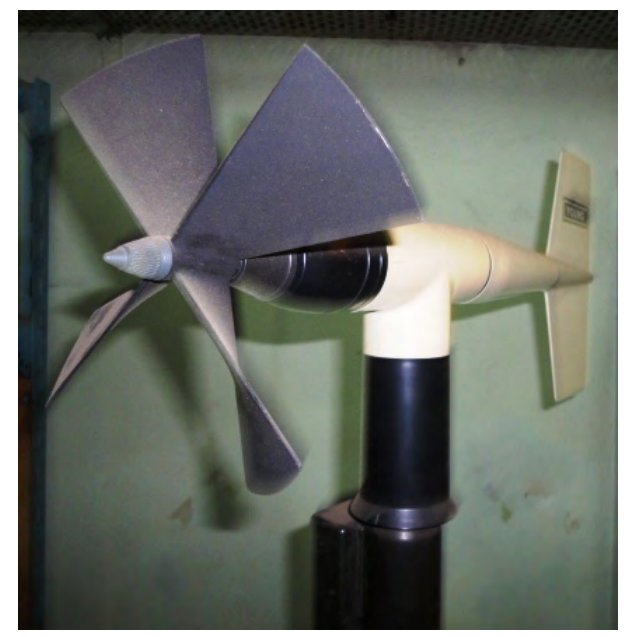

Fig. 7.1: Aerovane anemometer. (Photograph courtesy of Ricardo Zuazquita, Naval Hydrographic Service of Argentina).

Some particularly designed propellers have a variation of the rotational speed which is nearly a cosine function of the angle between the plane containing the propeller and the wind direction; it is said that these propellers have a cosine response. Two such propellers orthogonally mounted, and whose axes are in a plane parallel to the 
ground, may be used to determine the vector components of the horizontal wind. If a third propeller is added vertically, the vertical component of the wind can also be measured. Because the propeller response deviates from the cosine response for angles between $80^{\circ}$ and $90^{\circ}$, it is recommended by some government agency (US EPA, 2000) that users of vertical propeller anemometers should consult with the manufacturer on proper handling of the data.

The starting threshold of propellers depends on the mechanical design. When light weight materials such as molded plastic are employed, starting thresholds below $0.5 \mathrm{~m} / \mathrm{s}$ are achieved. More robust anemometers made of metallic parts may have thresholds between $0.5 \mathrm{~m} / \mathrm{s}$ and $1 \mathrm{~m} / \mathrm{s}$; accuracy is typically about $\pm 0.3 \mathrm{~m} / \mathrm{s}$. Once again the selection of the adequate anemometer depends on the use. Probably for polar regions with high winds and where frequent maintenance is not possible, $a$ robust metallic propeller should be selected.

Because of their relatively quick response times, these sensors (aerovanes) are also suitable for use in determining the standard deviation of the along-wind-speed fluctuations. Some sensors have distance constants of about one meter.

\subsubsection{Cups and Vane}

A cup anemometer is shown in Figure 7.2. It consists of three or four hemispherical or cone-shaped cups mounted symmetrically around a vertical axis of rotation. The three cup anemometer is recommended by some government agencies (US EPA, 2000). These sensors are omnidirectional, which means that the angular speed of the device is independent of the wind direction. They average the wind speed and direction in space, which is a useful characteristic because turbulent fluctuations can be considered, to some extent, as a spatial variable rather than a temporal fluctuation ([Kristensen, 1993). Cup anemometers are robust and easy to operate. The only precaution during installation is to make sure that the rotation axis is in the vertical direction. As with all mechanical anemometers they have an initial speed threshold and the transference has a useful linear range beyond which it loses sensitivity. When cup sensors are combined with a wind vane, they provide information about wind speed and direction.

There has been a considerable interest in understanding the dynamics of the cup anemometer (Kristensen, 1993), particularly in knowing its response when exposed to a turbulent wind. It has been found that cup anemometers 'overspeed', because they respond more quickly to an increase in the wind speed than to a decrease. For example, a robust cup anemometer for use in Antarctica (Fig. 7.3) was tested by the authors and it was found that it has a time constant of $0.5 \mathrm{~s}$ with a given increasing wind step, whereas for the same decreasing step the time constant was $4.5 \mathrm{~s}$. Thus, due to this "asymmetric" response, it is expected that the measured mean wind speed of a turbulent wind will be higher than the real one. 


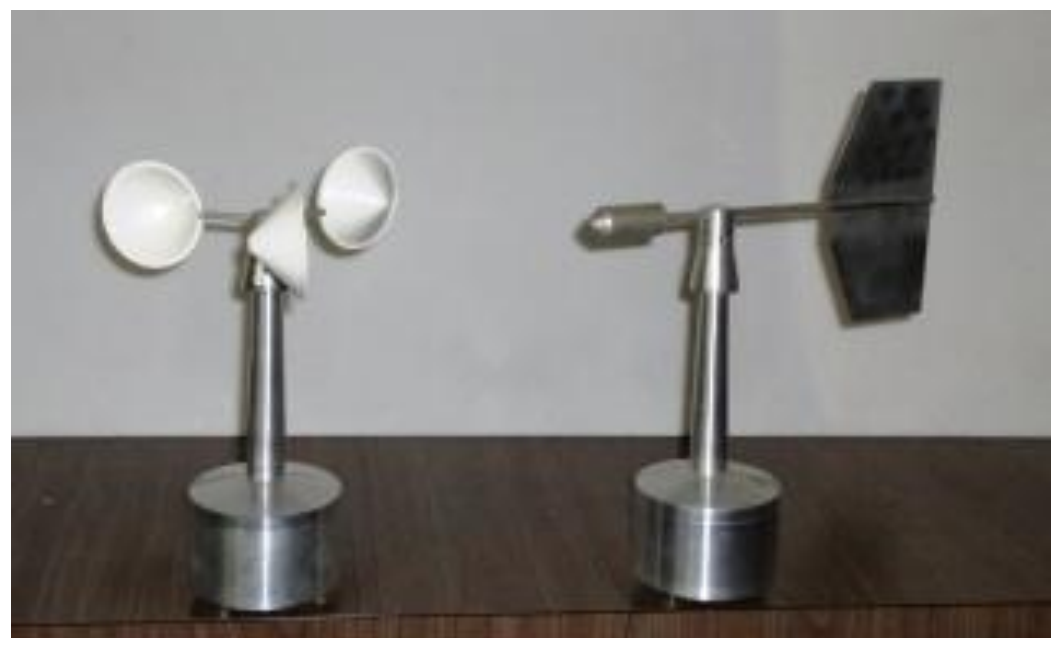

Fig. 7.2: (Left) Cup anemometer. (Right) Wind vane. (Photograph courtesy of Ricardo Zuazquita, Naval Hydrographic Service of Argentina).

The wind vane and the cup speed sensor are spatial filters of the wind speed and direction. When an anemometer is designed, it is important to match the distance constant of the vane to the distance constant of the cup. In this way both speed and direction would "filter" the information in a similar way, or in other words, both constitutive parts of the anemometer "average” approximately the "same wind” (Kristensen, 1993).

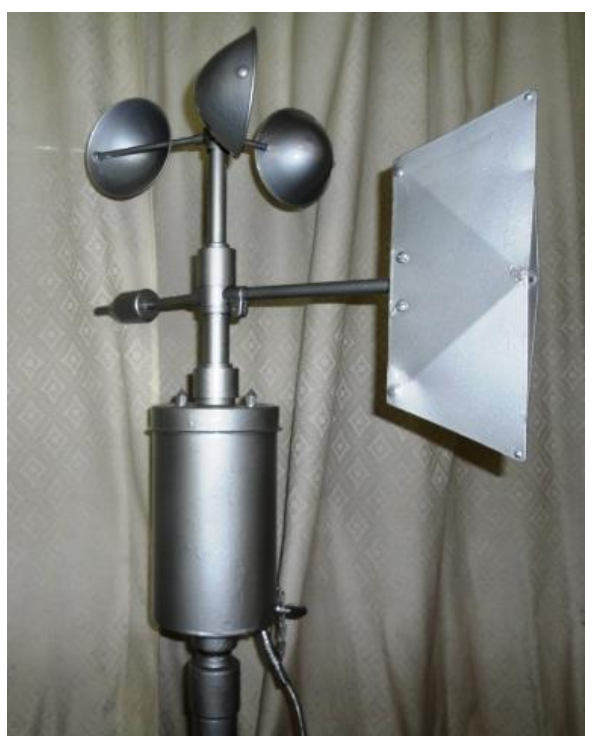

Fig. 7.3: Robust cup anemometer for use in Antarctica made of metallic parts. (Photograph courtesy of Ricardo Zuazquita, Naval Hydrographic Service of Argentina). 


\subsubsection{Electrical Information Proportional to Wind Speed and Direction}

As described in Sections (4.14.1) and (4.14.2), there are several operating principles to convert rotor and vane mechanical information into electrical information. According to Section (2.2), it is convenient that the anemometer's rotors (cups and propellers) produce an electrical signal proportional to their rotation rate (linear transference) and it would be suitable that this signal be easy to process and store. Beyond a starting threshold, rotors have a range where the relationship between wind speed and rotation rate is linear. Thus, an electrical device with linear electrical output as a function of rotation is a suitable solution. There is always a starting threshold due to shaft friction which could be increased by the transduction method used to obtain the electrical signal.

As stated above, those anemometers that generate electrical energy by means of a rotating shaft produce an electrical braking torque which poses some limitations in terms of achieving low thresholds and quick response times. Then these methods are not the most adequate when the mechanical energy available from the wind is low, because they tend to stop the shaft rotation. This effect is observed as an increase in the threshold of the transference, i.e. as an increase in the inability of the device to rotate when the wind velocity is low.

Optical devices where a light beam is interrupted by a rotating slotted disk are frequently used in applications where low thresholds are required because their small braking torque is due only to the shaft friction. As the cup or propeller rotates the slotted disk chops the light beam generating pulses on the photo detector. The pulsed output frequency from this type of transducer is proportional to the rotation rate. Pulses are easy to handle by digital systems since they are simply counted over a time window. The number of slots used in anemometers may be about 100 to eliminate signal fluctuations which may arise with low wind speeds (US EPA, 2000).

Some devices for measuring wind direction with a vane can also be found in Chapter 4. Potentiometers are a low-power consumption classical solution, but they suffer from maintenance problems associated with the friction caused by the wiper on the potentiometer track. Also, this friction drops the sensitivity of the vane to respond to low velocity winds. When electrical energy to supply instruments is not a constraint and the electronic circuits have some processing capability such as a microprocessor, optical encoded discs are a good choice because they do not have parts to wear out (Section (4.14.2)).

\subsubsection{Sonic Anemometers}

The first sonic anemometers were developed about 1950 for special purposes (Kaimal \& Businger, 1963). The initial application was further extended and at present they are used as an alternative to the traditional mechanical anemometers. Sonic anemometers consist of an array of acoustic transducers and a microprocessor-based 
electronic circuit. The array of transducers determines the capability of the instrument to measure wind velocity in one, two, or three axes. Most of the anemometer models use three orthogonal axes, each axis having two transducers. In the example shown in Figure 7.4 the transducer supports in the $x$ and $z$ directions are both in the same vertical plane, whereas the transducer support in the $y$ direction lies in a vertical plane perpendicular to the first.

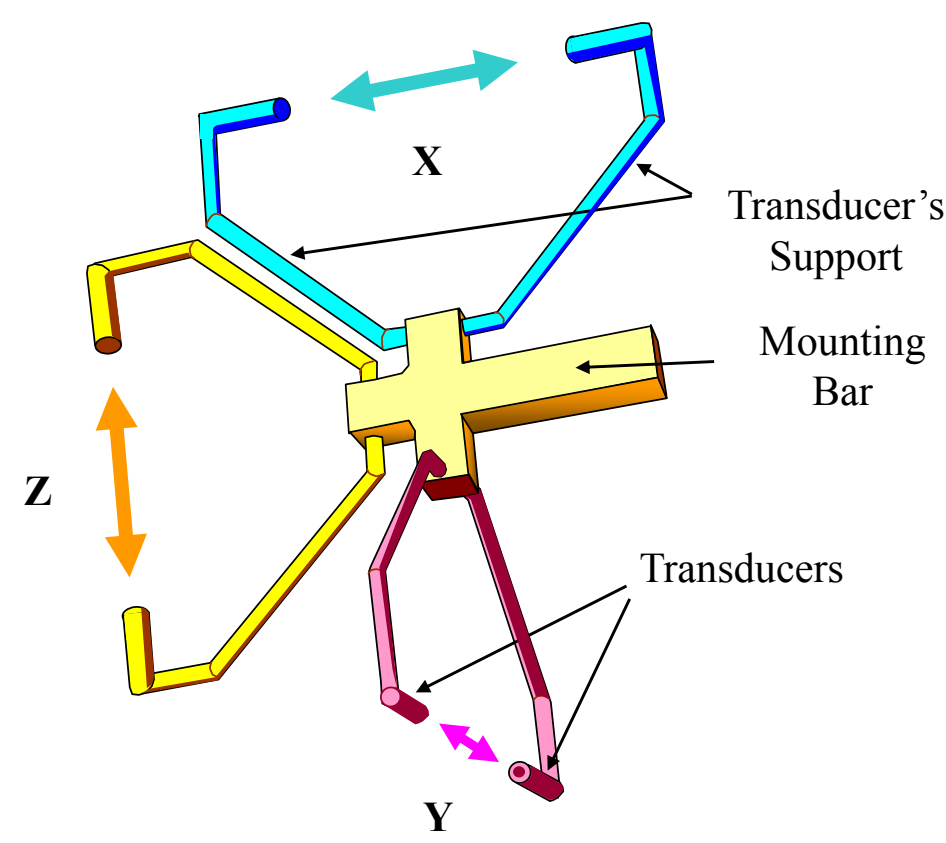

Fig. 7.4: The mounting bar holds the three transducer's supports. Each support keeps two faced acoustic transducers. The mounting bar is horizontal, $\mathrm{Z}$ and $\mathrm{X}$ are in a vertical plane, and $\mathrm{Y}$ is in other vertical plane, perpendicular to the first. The instrument's axis measuring the vertical component of wind is $Z$.

Under high speed horizontal wind conditions, the array that has three orthogonal axes produces some flow distortion because of the turbulence created by the transducer supports. In such cases, three non-orthogonal axes may be used where only the horizontal wind components are of interest (Fig. 7.5).

The ultrasonic transducers consist of piezoelectric crystals enclosed in metal housings; they are about $10 \mathrm{~mm}$ in diameter and $25 \mathrm{~mm}$ in length. Transducers are acoustically isolated from the housing and sealed to prevent contact with the outside environment. 


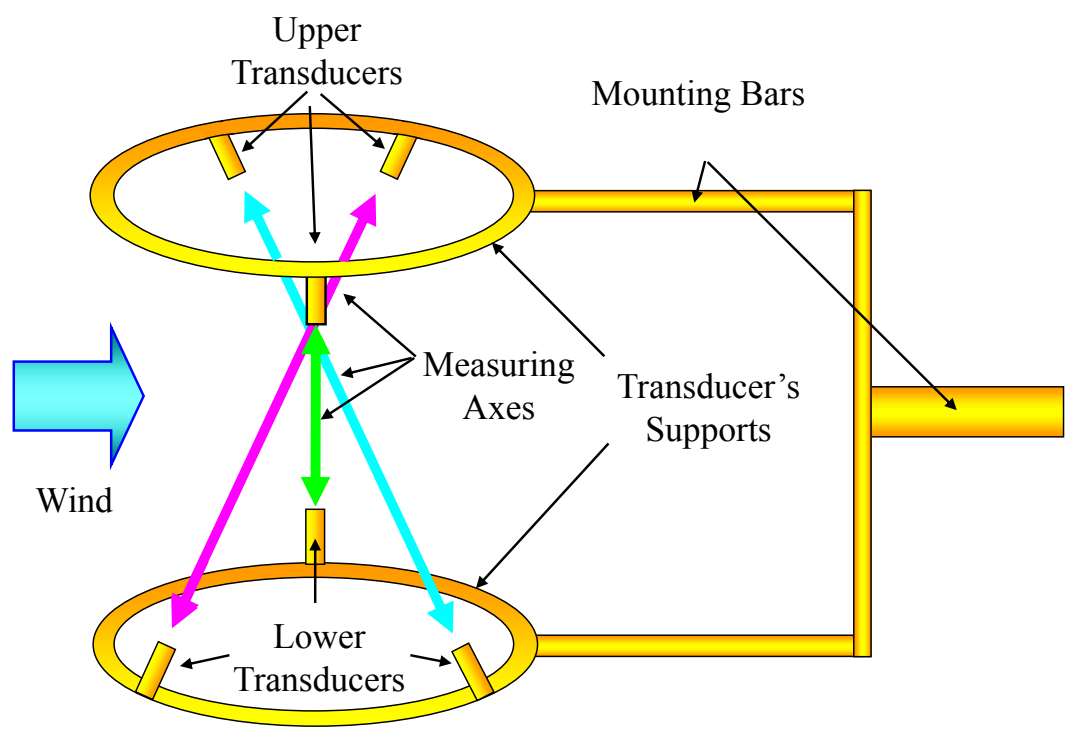

Fig. 7.5: The transducer's supports minimize the horizontal flow distortion. Each of the upper transducers faces one lower transducer.

By means of the electronic circuits, acoustic pulses are generated at one transducer and received by the opposite one. Figure 7.6 represents two transducers, A and B, separated by a distance $L$. The periods of time $t_{\mathrm{AB}}$ and $t_{\mathrm{BA}}$ are, respectively, the travel time required for the acoustic wave to travel the distance $L$ from the transducer A to $B$ and vice versa (Eqs. (7.3a) and (7.3b)). Based on the flying time of the pulses, the microprocessor calculates the wind velocity (Section (5.4.1)).

The system of equations (7.3a) and (7.3b) can be solved for the wind velocity component $v$ (Eq. (7.3c)

$$
\begin{aligned}
& t_{A B}=\frac{L}{c+v} \\
& t_{B A}=\frac{L}{c-v} \\
& v=\frac{L}{2}\left(\frac{1}{t_{A B}}-\frac{1}{t_{B A}}\right)
\end{aligned}
$$

Note that $v$ is the velocity component of the flow velocity $(\mathbf{V})$ in the direction of each pair of transducers $(v=V \cos \theta), \theta$ being the angle that $\mathbf{V}$ forms with the axis of the two faced transducers, and $c$ the speed of sound in air (which depends on the air temperature). These calculations are repeated for each of the orthogonal axes. 


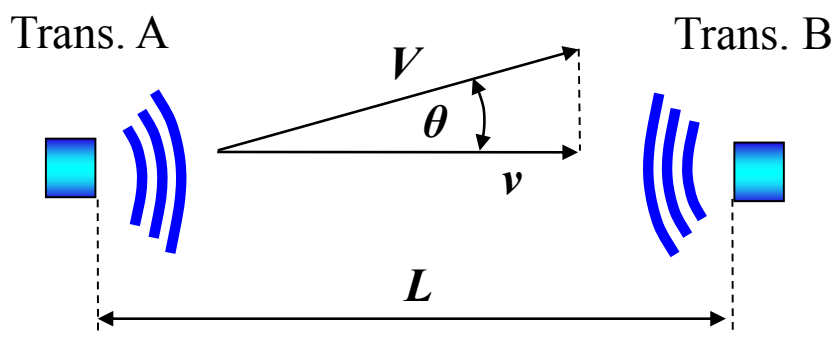

Fig. 7.6: Two faced transducers forming a measuring axis. A pulse is sent from $A$ and received at $B$ and vice-versa. The times of flight in both directions are measured. $L$ is the distance between transducers and $v$ is the component of the wind velocity $\mathbf{V}$ along the axis direction. $\theta$ is the angle between wind velocity and the axis direction.

The sampling rate is generally user selectable and the instrument can record as many as 10 samples per second. In turn, each one of these ten samples represents the average of several measurements (for example, 10 measurements).

This kind of anemometer may record each single component of wind velocity and does not require moving parts. Because each axis measures one component of the wind velocity vector along known direction axes, the composition of the total wind vector is straightforward. The maximum wind velocity may be between 15 and $60 \mathrm{~m} / \mathrm{s}$ (54 and $216 \mathrm{~km} / \mathrm{h}$ ), depending on the array sensor geometry. Accuracy is typically \pm $0.1 \mathrm{~m} / \mathrm{s}$.

\subsubsection{Comparisons of Anemometer Measurements}

A pair of examples will be analyzed to show that in some applications even different operating principles could give similar results, whereas the same principles could result in similar, but not identical measurements, in other applications. It should be noted that in the first case comparisons are made between averaged measurements, whereas in the second, dynamic behaviors are compared.

\subsubsection{Comparison of an Aerovane and a Sonic Anemometer}

Aerovane and sonic anemometers were compared for a particular aeronautical application (Fisch, 2010); the average and maximum wind speeds were analyzed. The aim of this study was to find the relations between both measuring systems (aerovane and sonic anemometers) in order to substitute the mechanical instrument by a sonic one. The aerovane had been working for years and historical data recorded with this technology had to be related to the new one acquired by the sonic anemometer. By means of this study, the values which relate both data sets were found. 
The comparative research consisted in analyzing data acquired during 6 days during the high wind season of a rocket launch center. The analysis considered both the average and maximum wind speeds for one and ten-minute time intervals.

The results showed that there was no significant difference between the results obtained from both instruments and for both time intervals (one and ten-minute time intervals). The data analysis of the two instrument time series showed that sonic measurements were a little higher than those from the aerovane; the differences for the averaged wind speed values were around $0.5 \mathrm{~m} / \mathrm{s}$. For maximum wind speeds, differences increase to a value around $1.0 \mathrm{~m} / \mathrm{s}$. Therefore, the researchers considered that to join the past data set acquired with the aerovane and the future data set to be acquired with the sonic anemometer, they only needed to add the above differences to the old data set.

This is an interesting result which shows that for some applications anemometers with different technologies may give comparable results.

\subsubsection{Comparison Among Different Cup Anemometers}

Wind power plants feasibility studies require knowledge of wind energy. An investigation of the characteristics of five commercial cup anemometers being used in wind energy has been carried out under wind tunnel and laboratory conditions (Pedersen et al., 2006). All anemometers had three conical plastic cups but differ in their mechanical design (cup size, shaft, bearing and body). They were analyzed to get their torque and angular response characteristics, and friction. The representative parameters of such devices were fitted to two different cup anemometer numerical models, which were used to simulate time responses under free field operational conditions.

It was observed from this study that even for similar anemometers, the details on the design of the cup, rotor, shaft, bearings and body have their influence on the angular and dynamic characteristics of the devices.

This work also shows 30-second time traces of the five cup anemometers compared to one propeller anemometer, all of them working at $8 \mathrm{~m} / \mathrm{s}$ wind speed. The graphs permit visualizing the magnitude of the so called "inherent turbulence", which characterizes most cup anemometers. The figures show that the variations of the cup anemometer readings are significantly higher than those of the propeller; the propeller readings look like a low pass filtered version of the cup readings.

These results show that propeller anemometers tend to spatially and temporally filter wind speed fluctuations, thus giving average values of wind speed. 


\subsection{Rain Gauges}

\subsubsection{Introduction}

Rain gauges are instruments used to gather rain precipitation. Also known as pluviometers, they are basically composed of two parts: a rain collector (usually a funnel) and a rain meter. The second may be as simple as a transparent graduated container (Fig. 7.7) that measures the volume of water precipitated in a given time period, for example 12 hours.

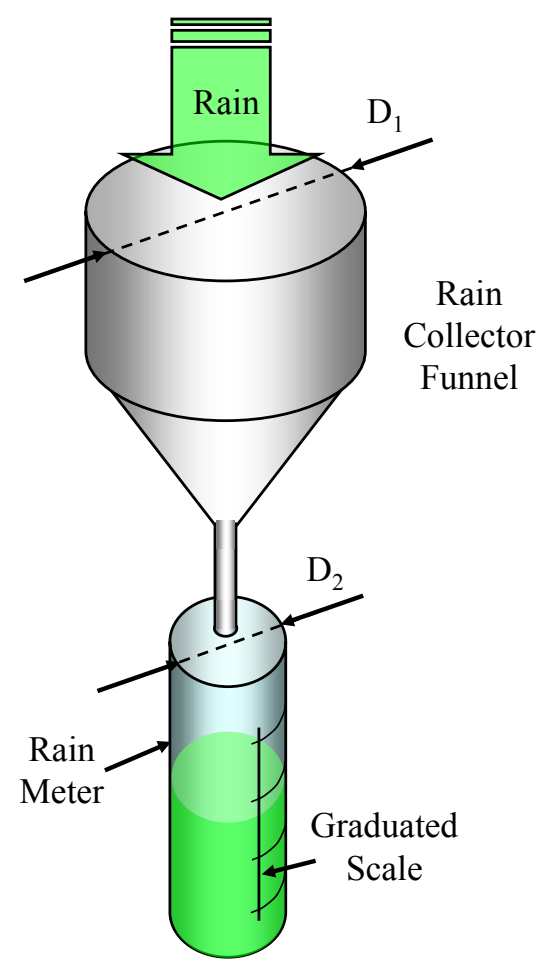

Fig. 7.7: A simple rain gauge or pluviometer

The rain volume measured in the container is referred to the area in which it was collected; then rain precipitation is generally expressed in millimeters. For example, if the graduated scale shows a height of $h_{2} \mathrm{~mm}$ that correspond to a collected volume of rain $V_{2}$, then the rain fallen $\left(h_{1}\right)$ in $\mathrm{mm}$ is given by

$$
h_{1}(\mathrm{~mm})=\left(\frac{D_{2}}{D_{1}}\right)^{2} h_{2}
$$


where $D_{1}$ and $D_{2}$ are the diameters of the funnel and the graduated container, respectively.

This simple description corresponds to a manual rain gauge. This elemental way of evaluating the fallen rain requires that a person pour off the device each time it reads the scale and enter the measured value in a spreadsheet at fixed time intervals, usually from once to three times a day. It should be noted that the data gathered in this way is an average value of the precipitation over the period between two readings. This average may be very useful for agriculture purposes but could not be good enough for other applications, e.g. for predicting floods in a city for evacuation alerts.

\subsubsection{Tipping Bucket Rain Gauge}

A more automatic way of measuring the rain precipitation is achieved by means of the tipping bucket rain gauge. It is also composed of a funnel that collects the rainfall and a different rain meter. Figure 7.8 shows a photograph of the internal parts of a typical tipping bucket rain gauge where the tipping bucket can be observed. The bucket is separated at the center forming two symmetrically divided containers and it can rotate round a pivot between two rest positions.

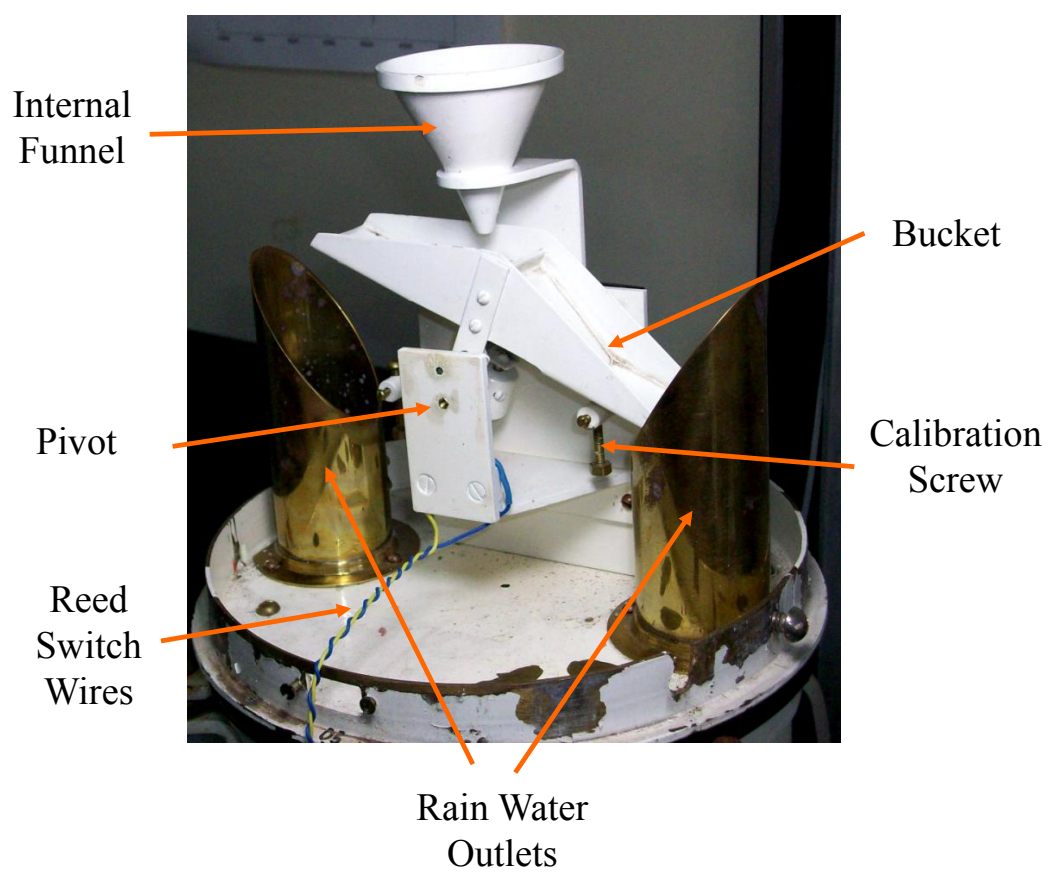

Fig. 7.8: Tipping bucket rain gauge. 
The external rain collector funnel discharges into the internal funnel, which in turn fills one of the bucket's containers. As it receives water the center of mass of the whole bucket changes; and it is forced to tilt towards the opposite rest position. A magnet attached to the bucket then activates a reed switch (Section (3.7.19)) when passing close to it (Fig. 7.9).

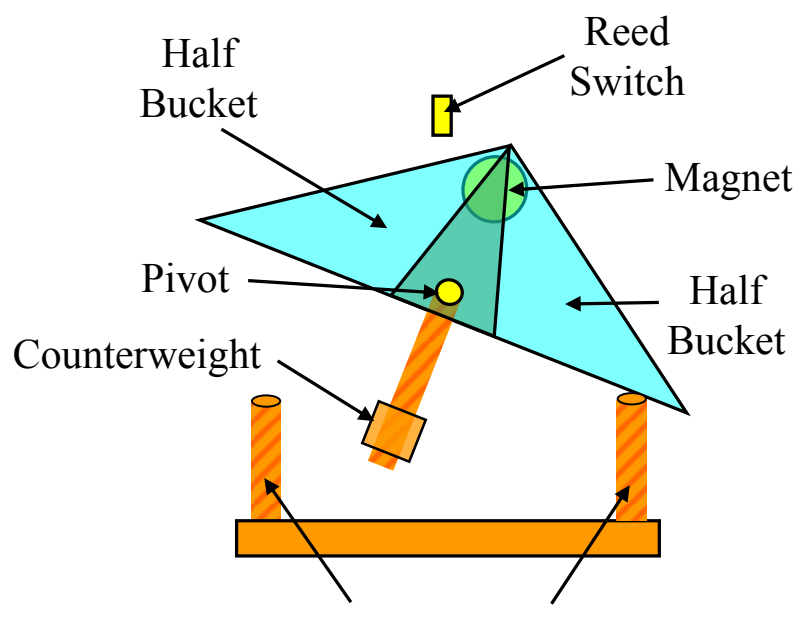

Calibration Screws

Fig. 7.9: Schematic of the bucket with the sensor (magnet and reed switch). Calibration is performed by adjusting the counterweight and the calibration screws.

The system is calibrated by means of a counterweight and a couple of calibration screws. Calibration is performed in such a way that each time the switch is activated a precise amount of water is discharged into the water outlets. Both outlets discharge in a common container placed below the rain meter. This container accumulates all the fallen rain, which permits the number of switch activations to be verified to see if they agree with the gathered volume.

Modern rain gauges have an electronic circuit with a precise clock. Thus, the amount of switch activations in a period of time is counted and recorded in memory. Generally, this period may be user selected; if a short period is selected, say ten minutes, it is possible to register the rain rate of strong short time precipitations.

In some applications such as flood warning in cities even ten minutes may be too much time, because to perceive a tendency at least three points are needed, which implies waiting at least half an hour. Then, for these kinds of applications it is required to register and transmit the instant at which the bucket is tipped. The instrument shown in Figure 7.8 was designed to evaluate the performance of the discharge ducts of a city during strong rain events. For this reason it has both possibilities: counting 
the dumps on a fixed time and registering the precise time when the bucket rotates. For flood warning this information has to be transmitted in real time. Figure 7.10 shows a precipitation of about $10 \mathrm{~mm}$ in 15 minutes. In order to get a discretized temporal axis, dumps were post processed and integrated over a period of one minute. After a delay of 15 minutes the water arrives to a discharge channel and its level begins to rise; 20 minutes later it reaches about $2 \mathrm{~m}$.

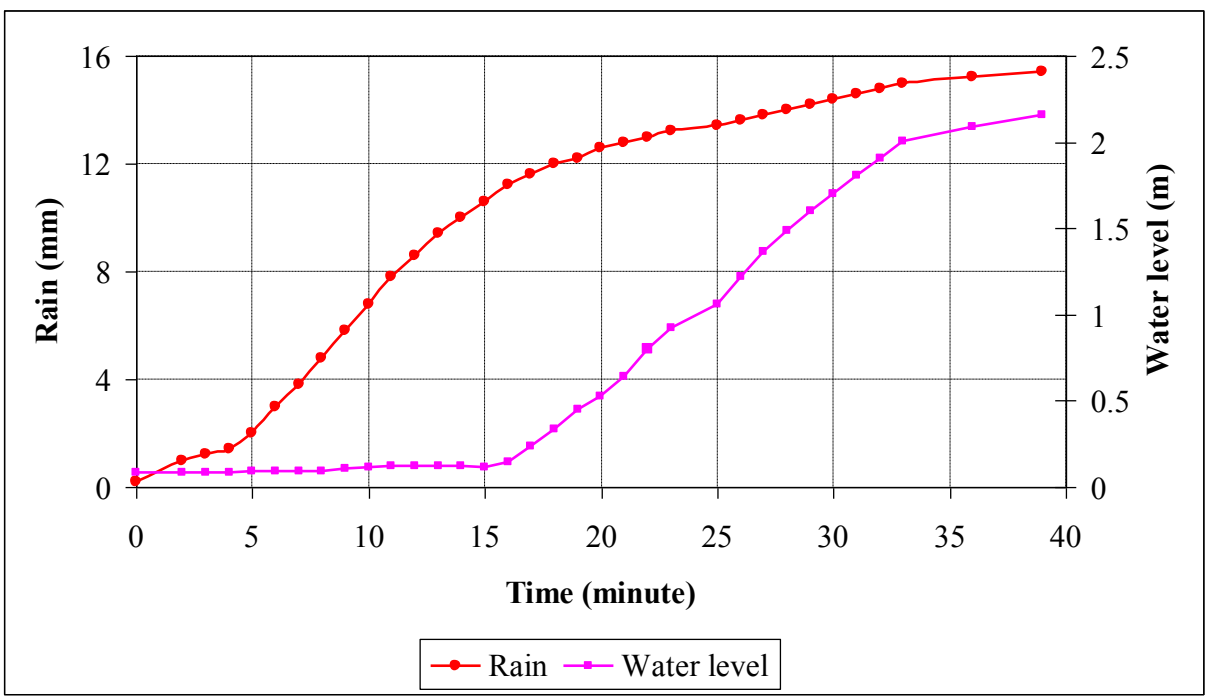

Fig. 7.10: Rain precipitation of about $10 \mathrm{~mm}$ in 15 minutes. The water arrives at a discharge channel whose level rises $2 \mathrm{~m}$ in 20 minutes.

The resolution of a tipping bucket is given by the volume of water that makes the bucket tip up. This volume is referred to the catchment area of the funnel and expressed in $\mathrm{mm}$. The World Meteorological Organization (WMO) recommends rain tipping gauges with a catchment area of $200 \mathrm{~cm}^{2}$ and a resolution of $0.1 \mathrm{~mm}$.

Because the rain gauge meter performance is based on a seesaw mechanism, it has to be installed leveled to work correctly. Some models provide leveling screws and a bulls-eye level for easy and precise adjustment in the field. For use in cold weather some models are provided with a heater to prevent the seesaw mechanism from freezing. A proper functioning of the device requires a periodical maintenance, birds perching and insects could clog the funnel. Figure 7.11 shows a top view of the internal funnel after a storm; insects have obstructed water flow in spite of the screen that covered the funnel. Students should be aware that these problems could occur and try to prevent them from happening. 


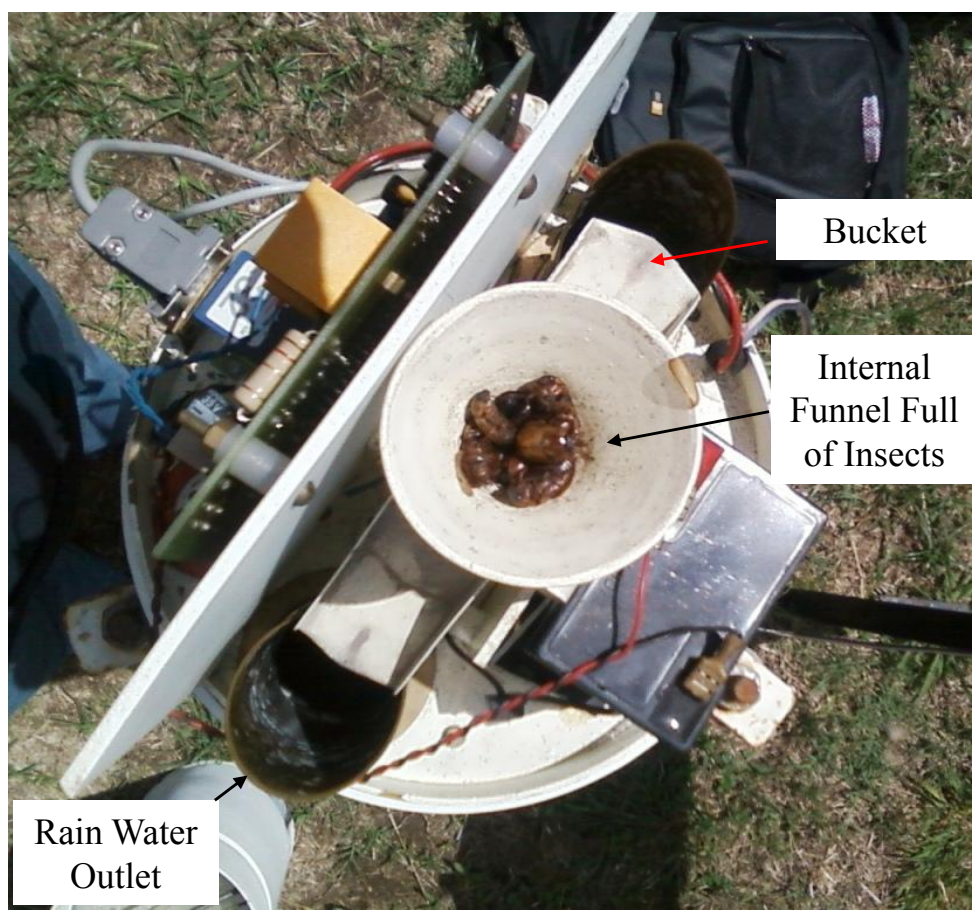

Fig. 7.11: Internal funnel obstructed by insects. It causes the overflow of the funnel and the distortion of measurements.

\subsubsection{Rain Gauges Without Moving Parts}

\subsubsection{Siphon Rain Gauge}

Most of the earth's surface is covered with water, and most of the rain information collected at sea in the past was due to ships. Rain gathered by ships suffers some problems due to the air flow pattern over the ship's superstructure: the roll, pitch and translation motion; the sea spray that is caught by the rain gauge, etc. It was found that placing rain gauges in meteorological buoys anchored at fixed positions in the ocean was a good solution to collect more and better data at sea. It is obvious that tipping bucket rain gauges cannot be used for this purpose due to buoy's motion; a particular rain gauge design with no moving parts is required for buoys.

There are some possible designs. One of them has the following components: a catchment funnel, a measuring device and a siphon to discharge the accumulated water (Fig. 7.12). The precipitation caught by the funnel is conducted to the measuring tube where the height of the water column is measured at fixed periods of time. The precipitation volume is referred to the funnel catchment area and expressed in millimeters. 
The measuring tube and the left vertical tube of the siphon are communicated at the bottom, so water has the same level in both. When the water reaches the siphon's upper bend level, a dumping triggers and the measuring tube is discharged through the siphon up to the zero level.

The height of water in the measuring tube may be measured in different ways. A capacitive measuring device is frequently used (Case \& Michelena, 1981; Holmes \& Michelena, 1983). In this case there is a central electrode coated with an insulating material. The electrode is the inner conductor of a cylindrical capacitor, the insulting material is the dielectric, and water works as the external conductor of the capacitor (Section (3.7.8)). Because in cylindrical capacitors capacitance is directly related to the capacitor's length, measuring the capacitance the height of water is known. For this purpose, a suitable electronic circuit is used to measure the capacitance and record the data.

Controlled heaters allow operation at very low temperatures and the collected snow is melted and measured as rain precipitation. The siphon process that empties the measuring tube, usually, lasts less than a minute.

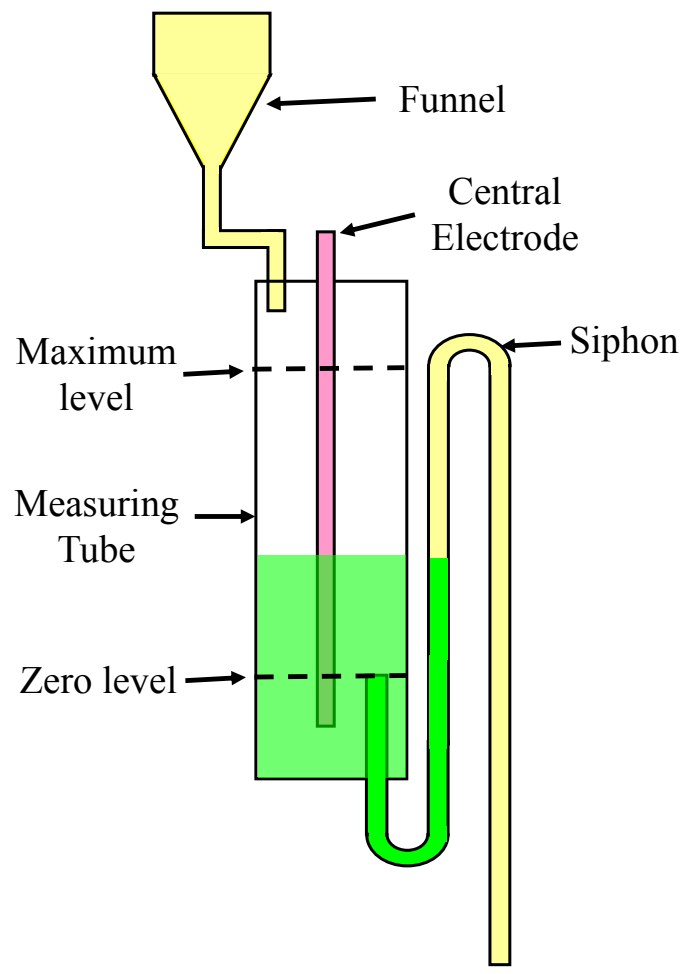

Fig. 7.12: Siphon rain gauge. 


\subsubsection{Optical Rain Gauges}

This technology is based on the alterations produced by raindrops in the propagation of a plane optical wave between a transmitter and a receiver. A raindrop illuminated by a plane wave creates a scattered field that can be considered as spherical waves emitted from the center of the raindrop. An interference pattern created by the incident plane wave and the scattered spherical wave, which depends on the raindrop size, appears at the receiver plane. Interferences are perceived on the receiving plane as shadows, which cause fluctuations in the received light intensity. These signals are known as optical scintillation.

Scintillations due to falling raindrops along the beam path allow rainfall rates to be estimated. The signature of the raindrop-induced scintillation is acquired on board the instrument, and its characteristics used to estimate rain parameters. This technology has been granted numerous international patents.

In early studies He-Ne lasers were used as transmitters (Ting-i Wang et al., 1979), photo detectors as receivers, and a distance of several meters between both was adopted. Present instruments (Fig. 7.13) based on this principle use a modulated near-infrared LED source as transmitter, a photodiode as a receiver, and the distance between source and receiver is about half a meter or even less (Ting-i Wang and J. D. Crosby).

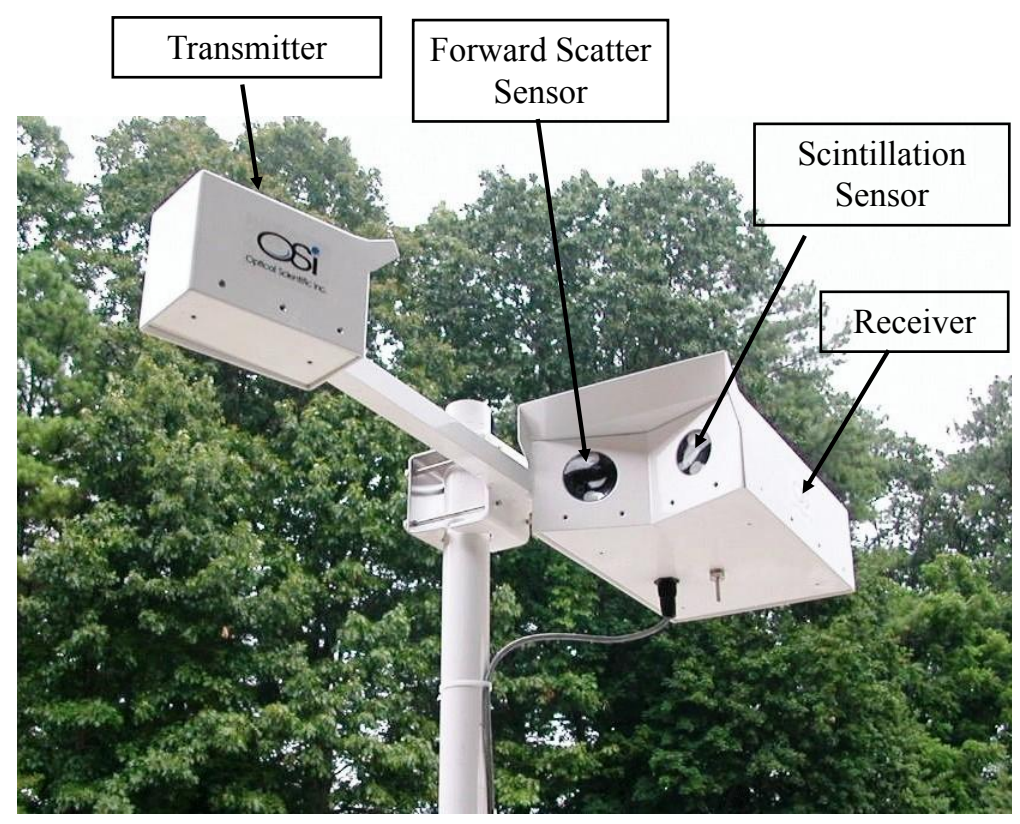

Fig. 7.13: Optical Rain Gauge with scintillation and forward scatter sensors. (Photograph courtesy of Optical Scientific, Inc. Gaithersburg, MD, USA). 
The horizontal beam makes the instrument sensitive to vertically falling raindrops, but not to horizontal (wind blown) ones. The height of the horizontal slot aperture of the receiver makes the sensor sensitive to precipitation particles but not to sand and dust. The short distance between transmitter and receiver permits both elements to be mounted on the same base, facilitating accurate alignment and easy transport and installation. Because moving parts are not needed, as is the case of the tipping bucket rain gauge, the optical rain gauge is suitable for deployment at ocean platforms such as ships and meteorological buoys.

Variants of the Optical Rain Gauges (ORG) that can differentiate between rain and snow are known as Optical Weather Identifiers (OWI). Some versions of the OWI (Fig. 7.13) combine the scintillation technology with an off-axis sensor that measures the optical forward scattering, which is sensitive to fog and drizzle. In order to discriminate ice particles from water droplets, some models add an acoustic sensor. All the information gathered by the three sensors is processed by a particular algorithm; field results show that the combination of the three technologies onboard a single instrument discriminates ice pellets and hail stones quite well (OSR 0303, no date). Various models of ORG and OWI have been used in airports, roads and hydrology applications.

\subsubsection{Weighing Gauge}

The principle of the weighing gauge consists in weighing the precipitation caught by a bucket. It is able to determine the precipitation of rain, snow or hail. For this purpose it uses a high-precision load cell to weigh the bucket contents and a temperature sensor for compensating the temperature changes in the load cell. The rainfall rate is obtained as the difference in rainwater accumulated over a given time interval. The bucket has to be emptied after a given period of precipitation to prevent it for overflowing. It can be emptied by hand of with the help of a pump. There are reports that mention some attempts to automatically drain the bucket but with limited success (Nystuen, 1999).

For temperature below zero, it is recommended to use antifreeze liquid because if the collected precipitation freezes completely, the collecting bucket could suffer severe deformations.

\subsubsection{Disdrometers}

They measure the drop size distribution and the rain rate. There are different operation principles but the most long-established disdrometers are based on the generation of an electric signal by every rain drop that hits the surface of a sensor.

One of these instruments is known as the Joss-Waldvogel disdrometer (JWD) (Fig. 7.14). It transforms the vertical momentum of impacting raindrops on a sensor into electrical pulses whose amplitudes $\left(U_{\mathrm{L}}\right)$ are given by 


$$
U_{\mathrm{L}}=k D^{\mathrm{n}}
$$

where $D$ is the drop diameter, and $k$ and $n$ are constants.

For a given particular design the sensor signal is amplified and the drop diameters in the range from 0.3 to $5.4 \mathrm{~mm}$ produce pulse amplitudes from 0.3 to $10 \mathrm{~V}$, respectively; for this range $k \approx 0.02586$ and $n \approx 3.7$ (a few changes in the design would produce different constants). The manufacturer provides the calibration table for 127 drop size intervals, but in order to reduce the amount of data a pulse height analyzer classifies pulse amplitudes into 20 size classes; the instrument records the number of counts on each class for a 30 s period.

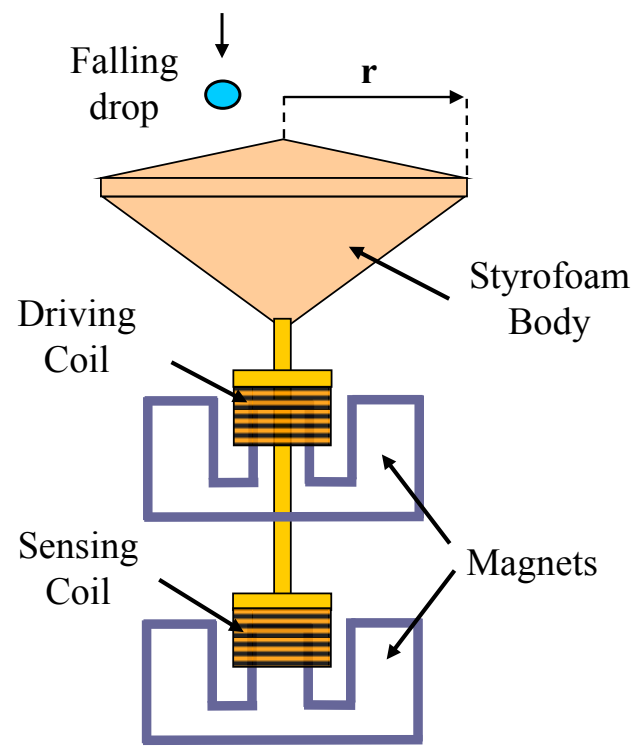

Fig. 7.14: Joss-Waldvogel disdrometer.

The sensor consists of two coils fixed to a conical Styrofoam body which receive the raindrop impact; one coil senses the drop impact and the other resets the initial position. The sensing and driving coils are placed in magnetic fields produced by two magnets. The kinetic energy of the drops produces a displacement of the conical body which moves de coils. On the moving sensing coil a voltage is induced according to Faraday's law (Section (3.7.12)). This signal is amplified and injected into the driving coil such that a force that opposes the displacement is generated. In this way the excursion of the sensor is reduced. Thus, it takes a short time to return to the original initial position being ready to measure a new impact. For a better understanding of the working principle see Sections (4.4.2), (4.4.3) and (4.13.2). The upper cone makes the raindrops slide so that the droplet impact area stays without water. If water remains on the top it will reduce the impact of the next drops on the sensor, modifying the sensor signal (Stijn de Jong, 2010). 
Once the relation between the sensor output signal and the drop diameter $(D)$ is known by means of a calibration process, the volume of fallen water $(V)$ can be calculated:

$$
V=\sum_{\text {all drops }} \frac{\pi D^{3}}{6}
$$

Because the radius of the sensor $(r)$ is known, $V$ can be referred to the surface of the sensor to express the rain in millimeters of height $\left(h_{1}\right)$ :

$$
h_{1}(\mathrm{~mm})=\sum_{\text {all drops }} \frac{D^{3}}{6 r^{2}}
$$

The amount of energy of a drop hitting the sensor depends on its mass and velocity. An assumption of the method is that the drops that hit the sensor have reached the terminal velocity (velocity remains constant). It is the velocity at which the resultant of upward and downward forces on the drop is null. Drops are not perfect spheres and the drop size is expressed with an equivalent diameter; it is the diameter of the drop if it would have been a perfect sphere.

Some precautions should be taken about the ambient acoustic noise of the place where the instruments will be installed. It has been reported (Tokay et al., 2003) that this type of disdrometer is sensitive to background audio noise. While a noise level of $50 \mathrm{~dB}$ or less had little effect on signals corresponding to drops, a noise level of $55 \mathrm{~dB}$ reduces the detected number of those diameters ranging from 0.3 to $0.4 \mathrm{~mm}$. When noise increased to $70 \mathrm{~dB}$, the detection of drops of $0.3-0.8 \mathrm{~mm}$ in diameter was almost completely suppressed.

\subsubsection{Piezoelectric Disdrometer}

The conical cap that prevents the puddle effect of the raindrops remains similar to the previously described one, but the generation of an electrical signal proportional to the raindrops energy is based on a piezoelectric disc (Stijn de Jong, 2010). A schematic of the sensor is shown in Figure 7.15.

The operating principle and equations are similar, but the way in which the impact of the drops is measured changes. This disdrometer was an attempt to make these instruments cheaper but this design still needs further improvement.

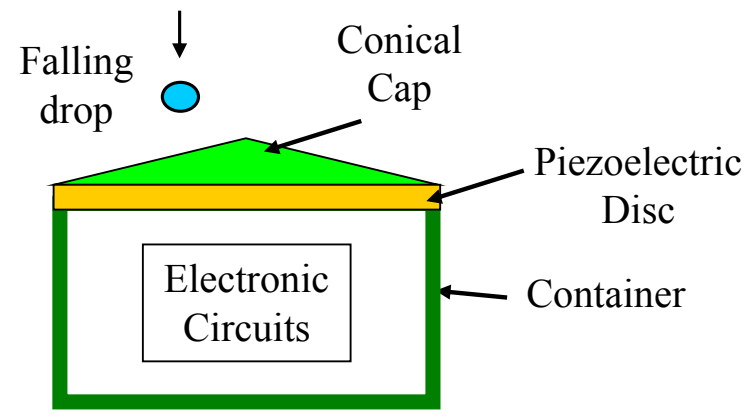

Fig. 7.15: Piezoelectric disdrometer 


\subsubsection{Acoustic Rain Gauge (ARG)}

When rainfall hits the surface of a body of water a particular underwater sound is generated; analyzing this sound a quantitatively measure of the rain can be obtained. The rainfall-generated acoustic underwater signals are louder than other sound sources such as breaking waves, biology, etc., and can be distinguished from them. The sound signature for different drop sizes has been studied (Ma \& Nystuen, 2005), thus the drop size can be estimated from the sound signatures. Estimates of drop size distributions can then be used to estimate the rainfall rate.

The frequency range of rainfall induced underwater sounds is from 1 to $50 \mathrm{kHz}$, the dominant sources of sound from raindrops being tiny bubbles trapped underwater during the splash. Large raindrops produce larger bubbles with a lower frequency sound $(2-10 \mathrm{kHz})$. The sound produced by large raindrops is highly correlated with the rainfall rate and can be used to detect and measure it.

The ARG used by Ma and Nystuen (2005) consisted of a hydrophone, amplifiers, band pass filters, CPU, a memory card, a data output and a battery pack. The signal is processed on board the instrument and the power spectra of several time series are averaged. The spectra are evaluated by means of special algorithms to detect the acoustic signature of the rainfall.

Results of several months of field work were compared with other rain gauges with good agreement. It has also been established that the acoustic signal from rain is wind speed dependent; at low frequencies the signal from rainfall is polluted by breaking waves sound. It is expected that this kind of rain gauge will be useful in ocean meteorological buoys where long time unattended instrumentation is needed.

\subsubsection{Comparative Analysis of Rain Measuring Systems}

An interesting work (Tokay et al., 2003) compares four impact Joss-Waldvogel disdrometers (JWD) and 27 tipping bucket (TB) rain gauges operated at 11 different sites during 44 days. Disdrometers were collocated with one or two rain gauges at all sites; collocated refers to gauges less than $2 \mathrm{~m}$ apart.

Analysis of data measured with two TB of the same model collocated at eight different sites, showed that the total mean percent errors were 1.3, 3.0, 3.1, 3.9, 4.2, 8.2, 13.8 and $16 \%$. Results from other field experiments, presented in the same work, show total mean percent errors of 0.8, 2.6 and $6.3 \%$. For those not already familiar with rain measurements, these results could be indicative of the errors that they could expect when measuring with instruments of the same manufacturer and model. Therefore, if instruments with different specifications or from different manufacturers are used in the study, perhaps the measurement spread could increase. Also, it is worth mentioning that out of the 27 TB deployed, some suffered problems, few of them due to vandalism, others to known causes and several to unknown failures. 
This indicates that if it is desired to avoid loosing valuable information, installing a redundant amount of instruments is advisable.

Tipping buckets (TB) rain gauges and Joss-Waldvogel disdrometers (JWD) were collocated at four sites. In this case, instruments with different operating principles were compared. In two of the four installations, disdrometers registers showed a lack of small drop data. It was attributed to the noise level generated by the drops hitting the surface of the metal roof at these sites. In another installation lack of particular sized drops were suspected to be due to the noise of a diesel generator used to power the equipments. For the total period of the research, in two of the four installations the disdrometers measure in excess of the TB with mean percent errors of 18.2 and $8.7 \%$. In the other two sites they measured 18.6 and 5.8\% below. As expected, when two different principles are used the spread in results increases. A valuable conclusion of this work is that the site to install the JWD requires being far from any sound background noise source because it reduces the JWD ability to detect small drops effectively.

We consider it necessary to mention some experiences reported by the authors (Tokay et al., 2003) because they are very enlightening for future users of these instruments and they can help to prevent foreseeable failures. Furthermore, we strongly agree with them.

Urban areas should be avoided to prevent vandalism.

Collocation of multiple gauges at a short distance is required.

Disdrometers should be collocated with at least two gauges.

Gauges should be calibrated prior to and at the end of each field campaign.

Gauges and disdrometers should be visited weekly for short field campaigns and biweekly for annual or longer operations.

\subsection{Instruments for Measuring Solar Radiation}

There are several kinds of instruments to measure direct and indirect radiation coming from the sun. They have different purposes and their geometries and optical properties are suited for these specific purposes, but all of them have some common features in their operating principles. Also, they have a common component called "radiation detector". Therefore, it has been considered that the simplest way to explain these instruments begins with the description of the detectors.

\subsubsection{Radiation Detectors}

The name of "radiation detectors" is given to sensors (Section (2.1)) that convert the radiation signal into an electrical signal. There are two methods to get the electric output in radiation detectors. In one of them, the radiation is first converted to a differential temperature; in the other, radiation is directly converted to an electric parameter. 
For instruments measuring radiation over a wide spectral range (pyrheliometers, pyranometers and pyrradiometers), transducers that convert radiation into temperature are frequently used (IAMAP, 1986). Most of the standard or reference instruments are of the thermal type. Instead, when measurements in particular spectral bands are required (sunphotometers), transducers with photoelectric outputs are preferred (IAMAP, 1986).

\subsubsection{Radiation to Temperature Conversion}

The incidence of solar radiation on a thermal resistor produces a temperature difference along the heat flow direction that is directly proportional to the received radiant energy. Thus, measuring the temperature difference along the resistor allows knowing the solar radiation. As stated in Section (4.7.4.2), thermocouples are well suited for differential temperature measurements; also, resistance thermometers and other temperature sensors could be used (Section (4.7)) to measure temperature on thermal resistors.

Thermal resistors for this application should absorb all the incident radiation arriving at them. With this purpose they are coated with special paints whose absorption coefficients are very close to 1 (they have very little reflectance). Furthermore, these resistors should not irradiate; for this reason they are of low thermal resistance so that the resulting temperature difference is low, thus reducing infrared losses (Fig. 7.16).

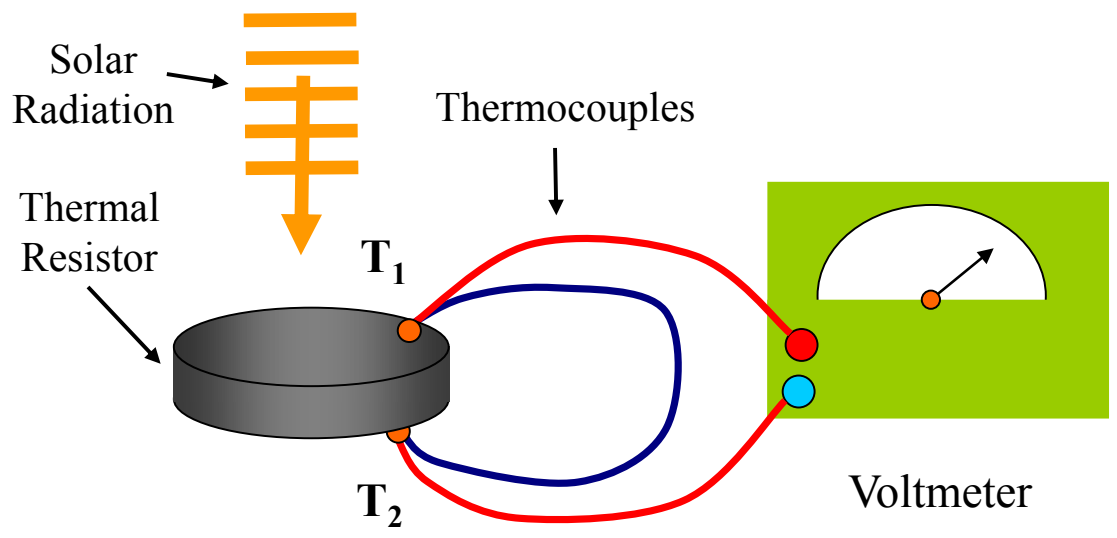

Fig. 7.16: Radiation to temperature conversion with a thermal resistor

With the purpose of getting an electrical output, the difference in temperature is measured by thermocouples which transform thermal energy into electrical energy. Only two thermocouple junctions are schematically depicted in the figure, but in a real device several junctions are placed on both measuring points summing up their 
voltages. This multiple junction arrangement, called a thermopile, increases signal level, decreasing noise influence. The junctions placed on the face receiving the radiation (temperature $T_{1}$ ) are called hot junctions, while those placed on the shaded face (temperature $T_{2}$ ) are called cold junctions. In general, cold junctions are on a metal body called a heat-sink which is at a constant reference temperature.

In this detector, the signal input suffers two changes, in the first step the incident light is converted into temperature, and in the second, temperature is converted to electricity.

\subsubsection{Radiation to Electric Energy Conversion}

In order to convert radiation directly into electric current, sensors based on the photoelectric effect are used; among them, photo-resistors and photodiodes are frequently utilized.

Photo-resistors are also known as light dependant resistors (LDR). When light with enough energy impinges on the semiconductor material of which the LDR is composed, photons produce free electrons. Thus, these special resistors exhibit a decrease in its resistance when illuminated.

Photodiodes are semiconductor devices which contain an interface in their crystal structure called a $\mathrm{p}-\mathrm{n}$ junction. Light impinging on the junction generates electronhole pairs, which gives origin to a photocurrent approximately proportional to the light intensity. Photodiodes can be operated also in a photovoltaic mode, generating a voltage when illuminated, but in this case light - voltage transference is nonlinear.

In LDR and photodiodes, radiation is directly converted to an electric parameter, without going through the conversion of radiation into temperature, as it was in the previous case.

\subsubsection{Instruments for Total Radiation Measurements}

Instruments to measure total radiation are those measuring the complete spectrum of the sun, the most known are pyrheliometers, pyrometers and albedometers.

\subsubsection{Pyrheliometers}

A pyrheliometer measures the direct component of solar radiation at normal incidence. The field of view of pyrheliometers is small to minimize the registration of circumsolar radiation; it frequently is between 6 and 10 degrees. For this reason, the radiation detector is placed at the lower end of a tube which restricts the view angle of the instrument by means of the field stop and the aperture stop (Fig. 7.17). There are different types of pyrheliometers based on similar ideas to measure the direct solar radiation. 


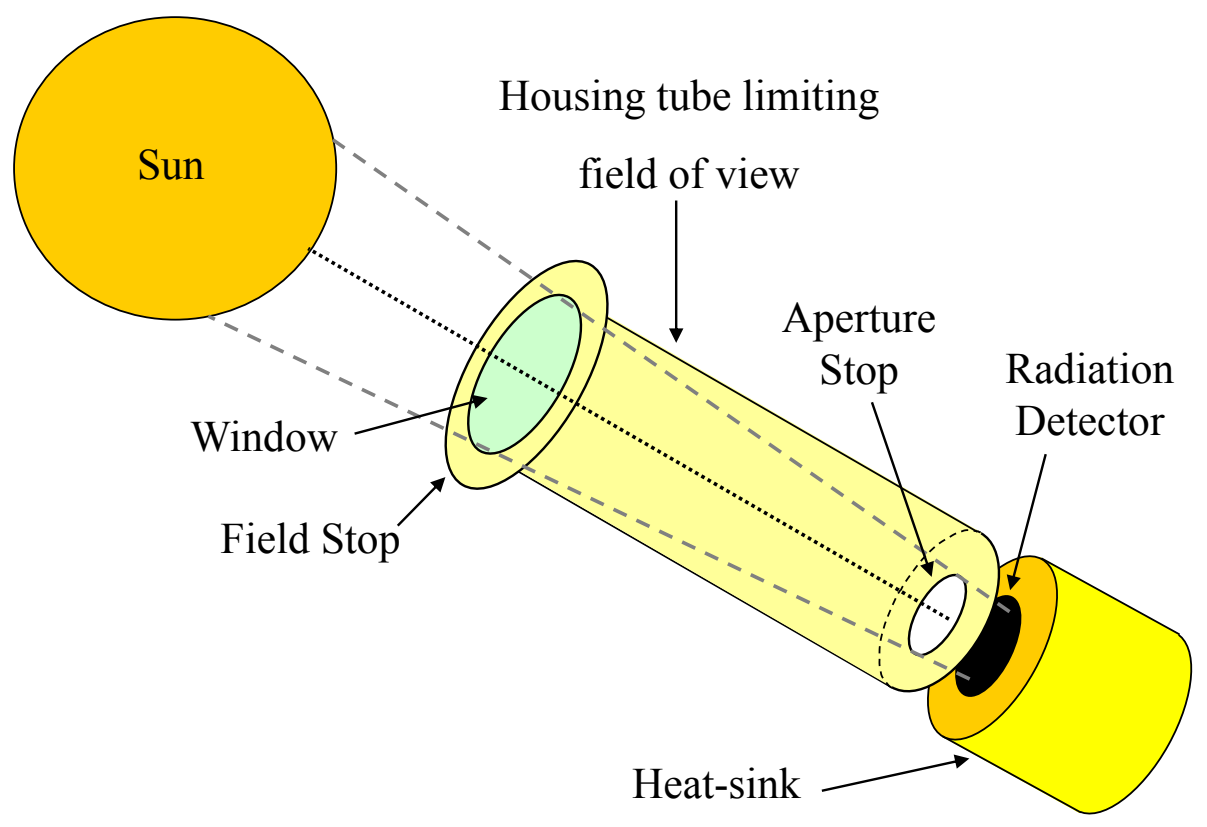

Fig. 7.17: A pyrheliometer

\subsection{Reference Pyrheliometers}

They are not found working as field instruments, nor are they of recent design, but because their design did not significantly change, the description of their operating principle helps to understand modern instruments.

1.- The Angstrom Compensation Pyrheliometer is a reference standard instrument. It has two strips of manganin (a resistive material whose resistivity is quite constant with temperature). These strips are coated with a black absorber and one of them is directly exposed to solar radiation while the other is protected from sunlight. The strip in the shadow is electrically heated until the temperatures of both strips equal.

When both strips are at the same temperature it can be said that the sun energy arriving at the detector per unit time equals the electric power provided by the current (i) to the manganin electric resistor, so Eq. (7.7) can be used to calculate the solar radiation $(S)$. Remember that power dissipated on a resistor is proportional to the square of the current through it (Section (3.7.7)).

$$
S=k i^{2}
$$

where $k$ is a constant that accounts for the geometrical and optical constructive factors of the pyrheliometer as well as for the resistor value. Temperature difference is measured by differential thermocouples attached to both strips. 
2.- The standard instrument of the Smithsonian Institution (USA) consists of two blackened cavities surrounded by a special chamber through which water flows at a constant rate. One of the cavities is exposed to solar radiation while the other is shaded and heated through electrical resistors (IAMAP, 1986). A null difference in cavities' temperatures is achieved by adjusting the electrical input to the resistive heaters of the shuttered cavity. Again the equality between solar and electrical energy is used to show up the solar radiation. Temperature difference is also measured by means of thermocouples.

In both standard instruments, obtaining a true irradiance value from the measured electrical power is a difficult task. It requires the accurate knowledge of the electrical power through the resistor, the aperture area (through which the radiation enters the tube), the amount of heat losses through the metallic wires of the resistor and sensor, the absorption coefficients of the cavity receiver as a function of the spectral range of the incident solar radiation, etc. (IAMAP, 1986).

Briefly, measuring solar radiation with this kind of instruments implies comparing the heat produced by the radiated energy with the heat generated by a known electric energy source. It is assumed that all the received energy is converted into heat, and that no heat loss exists. Because these conditions are difficult to achieve, a number of correction terms has to be employed in the calculations to account for deviations from the ideal values.

Pyrheliometers are usually supplied with mechanical adjustments to allow the movement of the housing tube in elevation and azimuth to point the instrument to the center of the sun. These adjustments may be done by hand or with some automatic device.

\subsection{Modern Pyrheliometers}

The operating principle of modern pyrheliometers is similar to the one described above, thus the following explanations are based on Figures 7.16 and 7.17.

The window of modern instruments (Fig. 7.17) is an optical filter that defines its spectral range. Generally they are chosen so that approximately $98 \%$ of the solar radiation spectrum is transmitted through the window and impinges on the detector.

As stated in Section (7.4.1.1), the detector consists of a thermal resistor and thermocouples. The top surface of the thermal resistor is black painted; this paint has a porous finish that helps to absorb more than $97 \%$ of the incident radiation. The paint is selected to have a constant absorption as a function of the radiation wavelength. Some manufacturers state that absorption is practically constant within $2 \%$ on the spectral measuring range (Kipp \& Zonen B.V., 2008). The characteristics of this paint have to be very stable over long periods of time because the transference of the instrument strongly depends on it.

The radiation entering the window arrives at the thermal resistor warming its surface. Heat flows through the resistor to the heat-sink which may be the 
pyrheliometer body (Fig. 7.17). The temperature difference along the resistor is measured by a thermopile composed of several thermocouple junctions. The thermopile generates a voltage directly proportional to the temperature and thus to the radiation. For this reason, the ideal transference of the instrument is a constant value called the sensitivity.

The constructive characteristics of the thermal resistor and the thermopile are somehow variables; therefore, each pyrheliometer has to be individually calibrated.

Direct solar radiation $\left(E_{D C}\right)$ expressed in $\left[\mathrm{W} / \mathrm{m}^{2}\right]$ is calculated by

$$
E_{D C}=\frac{V_{\text {out }}}{S}
$$

where $V_{\text {out }}$ is the output voltage of the thermopile [V] and $S$ is the sensitivity of the instrument $\left[\mathrm{V} \mathrm{m}^{2} / \mathrm{W}\right]$.

Even when instruments are designed for outdoor use and are almost hermetically sealed, sometimes, due to a difference between inner and external pressure, some moisture can enter the instrument housing. Condensation of the moisture inside the window decreases the radiation arriving at the sensor. This problem is solved using a desiccant (silica gel) inside the instrument. Also dust deposited outside the window would result in radiation underestimation. In order to keep accurate measurements the desiccant must be changed periodically and the window cleaned frequently.

Ultraviolet radiation downgrades the black paint on the sensor surface; therefore, for assuring the measurements quality, a yearly or every two-year recalibration is required. Recalibration is performed by comparison with a reference pyrheliometer.

In order to always point to the center of the sun, pyrheliometers can be mounted on an automatic sun follower called a tracker; it may be either of clock-driven or computer-controlled type. Some clock driven sun trackers have a GPS integrated receiver to automatically configure location and time data. Because the time is periodically checked by the GPS receiver any potential clock drift is corrected.

Other sun trackers are based in photo detector devices that sense the intensity of the sun on a surface perpendicular to the housing tube; they are called active sun trackers. The active trackers keep the instrument pointing to the maximum sun intensity by means of some electronic and software working on a two degrees of freedom mechanical motorized device.

\subsubsection{Pyranometer}

Ideally, a pyranometer measures radiation in an elevation angle ranging from horizon to horizon and over an azimuth range of 360 degrees. In other words, it is an instrument for the measurement of all hemispherical solar radiation, direct and diffused (IAMAP, 1986; Kipp \& Zonen B.V., 2013). In this instrument the sensor is horizontally placed so that the radiation arriving to it comes from the sun and the sky.

One model of pyranometer has a radiation sensor based on a thermal resistor, as that described for pyrheliometers (Fig. 7.18a). When radiation impinges on the sensor 
the developed heat flows through the sensor to the pyranometer housing which works as a heat-sink; the temperature difference on the resistor is measured by means of a thermopile. The temperature on the thermal resistor is affected by wind and rain; also, there are some long-wave radiation losses. Therefore, in this design, the sensor is protected by two glass domes to decrease the influence of the above factors.

Other pyranometers have a different shape for the radiation to thermal converter device; they have a disc divide into 12 equal circular sectors which are alternatively painted black and white (Fig. 7.18b). A thermopile formed by six pairs of junctions is place on the disk in such a way that hot junctions are on the circular sectors painted black and cold junctions on those painted white. Because the black and white surfaces have the same absorption factor in the infrared spectral region, the instrument is sensitive only to short-wave radiation (the signal we want to measure), and only one protective glass dome is required.

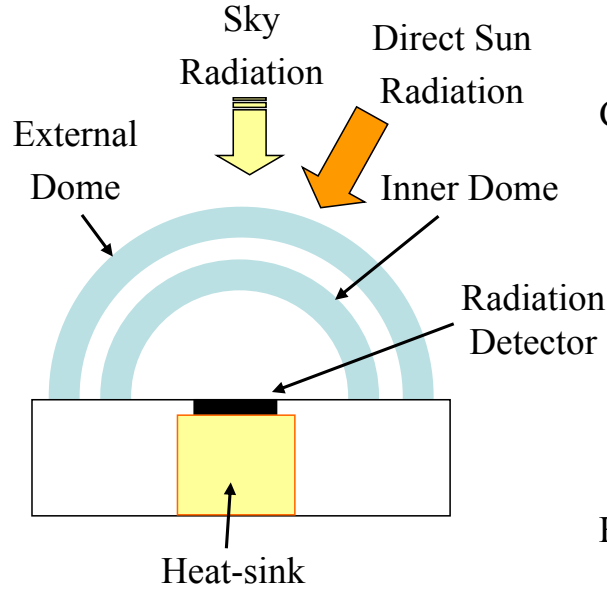

(a)

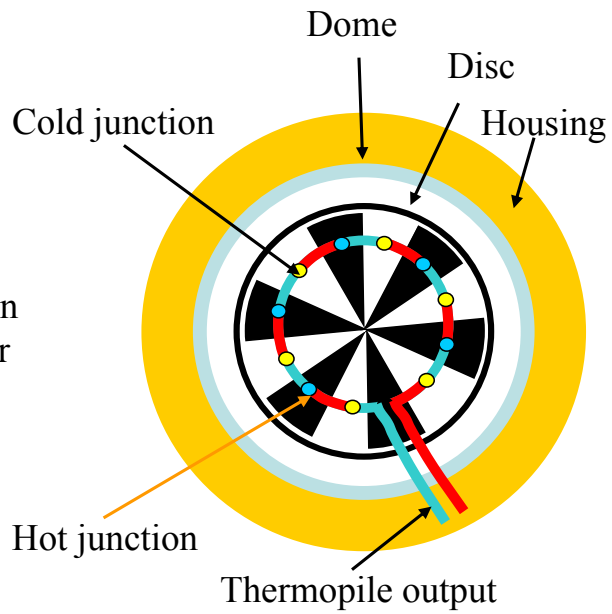

(b)

Fig. 7.18: Two models of pyranometes. (a) Lateral cross section view of a model which uses a sensor similar to that of a pyrheliometer and requires two domes. (b) Top view of the model which uses a disc divided into 12 circular sectors; it requires only one dome. In both models temperature is measured by a thermopile.

The glass domes of pyranometers work also as an optical filter with an approximately flat transference for the wave-length radiation range from 300 to $3000 \mathrm{~nm}$.

In order to collect radiation from the entire hemisphere of the sky, pyranometers have to be installed at a height of about $2 \mathrm{~m}$ above ground level. No obstructions should be above the horizon and no object (buildings, trees, etc.) should project their 
shadows on the instruments at any time of the day. The instrument must be mounted leveled on a platform free from vibrations.

Some operating problems that could lead to underestimation of the signals are dust or moisture on the external face of the pyranometer's dome. Also, the condensation of moisture inside the dome decreases the signal. Dust should be removed frequently with a brush and dew or frost eliminated by means of a fan producing a current of air over the dome. In general, an internal recipient with desiccant prevents moisture condensation inside the dome.

Calibration of pyranometers should be performed yearly and the recommended way is to place a secondary standard pyranometer alongside the operational instrument being calibrated (IAMAP, 1986). At least 100 samples from both instruments should be taken in diverse radiation conditions (clear and cloudy skies). The ratio between the two measures for each sky condition is calculated and averaged. This average together with the calibration factor of the secondary standard is used to estimate the new calibration factor of the operational instrument.

\subsubsection{Albedometer}

Albedo is the fraction of solar energy reflected from a celestial body that does not emit light by itself. It has been established that it takes values between 0 and 1, 0 being the albedo of a body which does not reflect any light and 1 the albedo of a body that reflects the entire incident light. For example, a surface on the Earth that reflects back into space $40 \%$ of the incident energy is said to have an albedo 0.4 (http://www. astromia.com).

Water is highly absorbent of sunlight, so it has a low albedo, but most sunlight impinging on ice covered with snow is reflected, so it has a high albedo. As an example, the albedo is about 0.15 for grass and 0.5 for dry sand (Kipp \& Zonen B.V., 2013).

A way of measuring the albedo is by using two pyranometers. A pyranometer is placed as usual, and a second one is mounted in an inverted position, pointing towards the floor. The upper pyranometer measures global solar radiation and the lower measures solar radiation reflected from the surface below. The albedo is calculated from the irradiance $\left(\mathrm{W} / \mathrm{m}^{2}\right)$ measured by both instruments. For this application, pyranometers should be at a minimum height of $1.5 \mathrm{~m}$ above ground level to minimize shadow effects and to attain spatial averaging (Kipp \& Zonen B.V., 2013).

\subsubsection{Spectral Measurements}

\subsubsection{Pyrradiometers and Pyrgeometers}

These instruments are designed for measuring long-wave irradiance on a plane surface coming from the hemisphere above the instrument. Pyrradiometers are sensitive to 
radiation of wavelengths from 0.3 to $60 \mu \mathrm{m}$ whereas pyrgeometers are sensitive to radiation from 2 to $60 \mu \mathrm{m}$ (IAMAP, 1986).

The operational principle is similar to the instruments previously described, where a thermopile on a thermal resistor is used to transform radiation into voltage. They can be installed upwards to measure downward radiation from the sky or downwards to measure radiation from the ground. In the second case instrument should be mounted 1 to $2 \mathrm{~m}$ above a uniform surface covered by short grass. Care should be taken to avoid interference of the mounting pole on the instruments.

\subsubsection{Filtered Pyrheliometers and Pyranometers}

Pyrheliometers and pyranometers measure all the solar radiation wavelength range. Then, if it is desired to measure only in some spectral band, it is possible to interpose special optical filters before the radiation sensor. Due to the non ideal transference of the filters, it is somewhat complicated to evaluate the solar radiation in the desired band with pyrheliometers. The problem increases in the case of the pyranometers because the transmission of a filtering dome depends on the direction of the incoming radiation, making the interpretation of such measurements somewhat questionable (IAMAP, 1986).

\subsubsection{Sunphotometer}

A sunphotometer is an instrument to measure only some spectral bands of the solar radiation. It uses a silicon photo-electric sensor as those described above in Section (7.4.1.2). The sensors themselves have a filtering behavior and optical filters are added to select specific narrow bands. The bandwidth of the filters is $5 \mathrm{~nm}$ for high-accuracy instruments. The WMO recommends a minimum of three wavelength intervals centered at 368, 500 and $778 \mathrm{~nm}$ to measure aerosol optical depth. A sunphotometer for additionally measuring ozone, water vapor and nitrous oxide would need to measure in twelve spectral bands. Silicon detectors are sensitive to temperature changes. Therefore it is required to measure the temperature of the detector to apply a correction factor or to control the temperature of the detector by heating it.

\section{References}

Case, B., \& Michelena, E. (1981). Rain gauge for NOAA data buoys. IEEE/MTS Symposium, Oceans 1981, Marine Technical Society, Boston, MA, 463-467.

Fisch, G. (2010). Comparisons between aerovane and sonic anemometer wind measurements at Alcântara Launch Center. Journal of Aerospace Technology and Management, 2(1), 105-110.

Holmes, J., \& Michelena, E. (1983). Design and testing of a new rain gauge for NDBC meteorological data buoys. Fifth Symposium on Meteorological Observations and Instrumentation, Toronto, ON, Canada, American Meteorological Society, 34-37. 
IAMAP (International Association of Meteorology and Atmospheric Physics - Radiation Commission). (1986). Revised Instruction Manual on Radiation Instruments and Measurements. Claus Frohlich \& Julius London (Eds)., WCRP Publications Series No. 7, WMO/TD - No. 149.

Kaimal, J.C. \& Businger, J. A. (1963). A Continuous Wave Sonic Anemometer - Thermometer. Journal of Applied Meteorology, 2, 156-164.

Kipp \& Zonen B.V. (2008). Instruction Manual. CHP Pyrheliometer. Delft, The Netherlands.

Kipp \& Zonen B.V. (2013). Instruction Manual. CMP series Pyranometer, CMA series Albedometer. Delft, The Netherlands.

Kristensen, L. (1993). The Cup Anemometer. Ris ø-R-615(EN). Risø National Laboratory, Roskilde, Denmark.

Kristensen, L., \& Hansen, O. F. (2002). Distance Constant of the Risø Cup Anemometer. Ris $\varnothing-\mathrm{R}-$ 1320(EN). Ris $\varnothing$ National Laboratory, Roskilde, Denmark: Pitney Bowes Management Services.

Ma, B. B., \& Nystuen, J. A. (2005). Passive Acoustic Detection and Measurement of Rainfall at Sea. Journal of Atmospheric and Oceanic Technology, 22, 1225-1248.

Nystuen, J. (1999). Relative Performance of Automatic Rain Gauges under Different Rainfall Conditions. American Meteorological Society, 16, 1025-1043.

OSR 0303 (Optical Scientific Report 0303). WIVIS with HIPS sensor performance. Optical Scientific, Inc., Gaithersburg, MD 20878-4008 USA.

Pedersen, T. F., Dahlberg, J. A., \& Busche, P. (2006). ACCUWIND - Classification of Five Cup Anemometers According to IEC61400-12-1. Risø-R-1556 (EN). Risø National Laboratory, Roskilde, Denmark.

Stijn de Jong. (2010). Low cost disdrometer. Improved design and testing in an urban environment. Master Thesis report, Delft University of Technology.

Ting-i Wang, Earnshaw, K. B., \& Lawrence, R.S. (1979). Path-Averaged Measurements of Rain Rate and Raindrop Size Distribution Using a Fast-Response Optical Sensor. Journal of Applied Meteorology, 18, 654-660.

Ting-i Wang, \& Crosby, J. D. Taking Rain Gauges to Sea. Global Climate Monitoring Gets New Tool: Rain-Induced Optical Scintillation for Measuring Precipitation at Sea. Reprinted from Sea Technology magazine. Optical Scientific, Inc. www.opticalscientific.com.

Tokay, A., Wolff, D. B., Wolff, K. R., \& Bashor, P. (2003). Rain Gauge and Disdrometer Measurements during the Keys Area Microphysics Project (KAMP). Journal of Atmospheric and Oceanic Technology, 20, 1460-1477.

US EPA (United States Environmental Protection Agency). (2000). Meteorological Monitoring Guidance for Regulatory Modeling Applications. EPA-454/R-99-005, Office of Air Quality Planning and Standards.

WMO (World Meteorological Organization). (2008). Guide to Meteorological Instruments and Methods of Observation, WMO-No. 8. Seventh edition.

http://www.astromia.com/glosario/albedo.htm 